\title{
Male Dominant Sport: The Challenges of Esports Female Athletes
}

\author{
Nur Hafizah Yusoff* and Yuza Haiqal Mohd Yunus \\ Department of Anthropology and Sociology, Centre of Social, Development and Environment, Faculty Social \\ Sciences and Humanities, Universiti Kebangsaan Malaysia, 43600 Bangi, Malaysia
}

\begin{abstract}
This article discusses the challenges experienced by female athletes in esports. Esports is categorized as a male-dominated sport. Since most of the players are male, female athletes struggle to sustain their careers. A qualitative approach was used where ten women who were actively involved in esports were interviewed. The respondents selected through the purposive sampling method were active in esports, representing esports team/club, and involved in massively multiple online role-playing games (MMORPG). Data were analyzed using thematic analysis and presented descriptively and narratively. The findings indicated gender stereotyping women as not competitive at MMORPG, sexually explicit comments from male opponents, communication issues, especially with male players, and the perception that women are not suitable to

ARTICLE INFO

Article history:

Received: 23 February 2021

Accepted: 15 May 2021

Published: 30 June 2021

DOI: https://doi.org/10.47836/pjssh.29.2.35

E-mail addresses:

nur_hafizah@ukm.edu.my (Nur Hafizah Yusoff)

yuzahaiqa196@yahoo.com (Yuza Haiqal Mohd Yunus)

*Corresponding author

play the extreme, aggressive and masculine type of online games. The game features are more significant to men compared to women, who are often associated with femininity. Indirectly, such impressions hamper the opportunity for women to be more active and progressive in esports.

Keywords: Female athletes, esports, gender, minority, sociology, stereotype
\end{abstract}




\section{INTRODUCTION}

The advancement in information technology has led to the growing usage of the internet among users for various purposes globally. Apart from the emerging social media applications that facilitate the communication process (Salleh et al., 2019), technological and digital developments also made a difference in the sports world. Online video games on computers and smartphones attracted children, teenagers, and adults. In the past, online video games were not considered to be beneficial to players.

Esports is a computer-based sport played by professional players or gamers in formal competition between teams via an electronic system (Edward, 2013). Many popular video game genres were contested, for instance, Strategy Base Game, First Person Shooter (FPS), Multiplayer Online Battle Arena (MOBA), and Player Unknown's Battlegrounds (PUBG). In Malaysia, strategy-based computer games such as Defense of the Ancients 2 (DOTA2) and League of Legends (LOL) are of interest among adults. These two games are based on the online battlefield strategy involving several players battling using powerful units known as heroes and assisted by their allies. The revolution of computer gaming technology has changed the context of the digital game itself owing to its highly interactive features that connect virtual players seamlessly across national borders, where players can interact and create a virtual community of young people (Yusoff, 2020). Moreover, online games provide the players with space and power to express themselves (Salleh \& Ilham, 2017) through the skills and techniques of the games they play. In 2017, Mineski Events Team (MET) President Kenchi Yap announced the national esports competition, the Malaysian Esports League (MESL), which was the largest DOTA 2 competition to date in Malaysia with a cash prize of up to RM500,000 to encourage the country's youth and overseas players to participate (Hayes, 2007). The significant amount of prizes is one of the major attractions in this sport (Yusoff et al., 2020).

Malaysian esports icons include 'Mushi' Chai Yee Fung, 'Ohaiyo' Khoo Chong Xin, 'MidOne' Cheng Yeik Nai, and 'Ah Fu' Tue Soon Chuan, who have successfully raised the country's name in the international arena (Lee \& Schoenstedt, 2011). Esports are monopolized by young people around the age of 16 to 30. On May 1, 2015, the Malaysian Electronic Sports Association was officially launched to focus on electronic games competition and related promotional activities. The association was registered with the Malaysian Sports Commission. Men still monopolize the majority of esports players both in Malaysia and abroad. As such, esports is conceptualized as a maledominated industry. There is no doubt that a small number of women have successfully ventured into the esports industry, especially in Malaysia. However, this number is still relatively small compared to male players. This article aims to discuss the factors that influenced female athletes who joined esports and their challenges. 


\section{LITERATURE REVIEW}

\section{Evolution of Esports}

Esports may be a newly introduced concept. However, 'virtual sports' has been around since the computer was invented and game consoles were introduced (Chikhani, 2015). Tennis for Two was the first virtual sport introduced to viewers in 1958 (Lynch, 2016). Tennis for Two was created by displaying an image of a tennis court on a computer, and the player must move the tennis ball by touching the screen, much like today's online games. In 1967, Ralph Baer created a game known as Brown Box, the first online game that used a button console to control the game, and it also appeared on television sets (Bradmore \& Magus, 2016).

The first online game started around the 1980s and was known as the Space Invaders Tournament (Edwards, 2013). The competition drew more than ten thousand entries and paved the way for esports. Nevertheless, the great start to the esports industry began in 1998 when the StarCraft game was introduced. The game uses a 'matching' game method that allows players to play with anonymous players (Lynch, 2016). Strategy and technique are fundamental to play the StarCraft game, becoming a phenomenon in many countries. In 2012, League of Legends (LOL) took over as the world's leading online game. The game was estimated to have over 100 million players (Milne \& McDonald, 1999) worldwide. Shortly after LOL, MOBA was introduced and triggered global attention. MOBA focused more on teamwork, especially team communication, to formulate success strategies (Everson, 2013). Nowadays, more games in esports are being introduced and not only focused on action and multiple roles. Games like football are also included in esports or better known as FIFA 20.

\section{Differences Between Male and Female Esports Athletes}

Women often become subordinates in conventional sports where their capabilities and achievements were compared to male athletes (Shen et al., 2016). A similar observation was noted in the virtual sports industry. Although esports do not involve physical contact with players, they are quite synonymous with being aggressive and violent. Hamari and Sjöblom (2017) provide an example of an online game, CounterStrike: The Global Offensive, which requires players to shoot their opponents to win the match. Also, the enjoyment of playing an online game and the excitement of winning a game or stepping into a higher ranking were reported to be more exciting for male than female players (Ray, 2004). Winning a match was stated to be the biggest goal for most esports male players (Bettencourt \& Miller, 1996), while female players were less concerned about winning or losing a game (Ray, 2004). This was attributed to openness to defeat and victory in a game by the female players (Shen et al., 2016). Most of the online games were designed to attract male over female players. Games such as MOBA, LOL, and StarCraft are based on war, action, and interspersed with violent elements, which are more suitable for male players (Hamari, 2013). 
These features represent more of the masculine image than the feminine. Indirectly, it answers the question of why more men are interested in esports than women. Female players were regarded incapable compared to male, and in some situations, female players were unsure of their skills (Shen et al., 2016). This issue was ascribed to female players' learning techniques and methods used in esports games (Blumberg \& Sokol, 2004). According to Bonanno and Kommers (2008), the longer time spent for esports training by the male players was the key for their good performance compared to the female players, especially for multiple online role-playing games (MMORPGs). Besides that, a lack of confidence among female players is another factor for their poor performance in esports games (Chan, 2008). Women tend to believe that men are more apt to be actively involved as role players as most of the esports involve science, math, engineering, and technology. Apart from that, the prizes offered were also different for male and female players. Ruvalcaba et al. (2018) stated that male players were often paid higher wages for their good skills and technical ability than female players. Female players play a passive role as supporting players in esports (Shen et al., 2016). Overall, the abovementioned factors resulted in biases in the player's position and pay scale.

\section{Female Athletes and Their Challenges in Esports}

Involvement in the male-dominated and behind-the-scenes sports industry has indirectly led to the emergence of a gender stereotype, especially to female players. Women are a minority in the esports industry. Yee (2006) mentioned that $86 \%$ of MMORPG players were male, and 14\% were female. Women involved in esports are sometimes confronted with sexism and sexual harassment (Ruvalcaba et al., 2018). Women images in games such as Mobile Legends, PUBG, and Dead or Alive were portrayed dressed in swimsuits or undergarments and some cases, with images of women's body parts exposed. Although the images were animated, they provide the stigma and perspective that a woman is deeply related to sexual elements but not ability, skills, and techniques.

In most online games, female characters are usually supporting roles, while the main characters are male (Beasley \& Collins, 2002), which caused female players to stand out as men. Reaching a higher rank or leaving the supporting role is the dilemma for female players. Moreover, most of the multiple-player online role-playing games like DOTA, PUBG, and Mobile Legends are aggressive and violent. A study conducted by Nielsen (2009) found that female players were more likely to choose online games that are less aggressive and violent. Shooting and multiple roles games attracted more male players than female players.

The capabilities of female players are often underestimated. For most male players, female players are not efficient and do not have a good game-playing technique (Witkowski, 2014). As a result, some female 
players deliberately hide their gender in an online game (Witkowski, 2014) and prefer to use male names to avoid gender stereotyping. In a team game such as the massively multiple online role-playing games (MMORPG), most teams consist of only one gender. However, some teams have a mixture of male and female players. In a team where there are both genders as players, the female players often feel depressed, especially when their team is losing. Being the victims of gender stereotyping, female players were regarded to affect their team's performance (Kaye \& Pennington, 2016) due to their incompetency and lack of skills (Gray, 2012), leading to the team's losses. Thus, female players prefer to form groups of females to prevent negative comments that could affect their emotions. The stigma and gender role stereotyping begin from the socialization process in their early upbringing.

\section{Effects of the Challenges on Female Esports Athletes Performance}

Sexual harassment can affect female athletes both emotionally and physically, not only in traditional sports but also in esports. It can indirectly cause emotional stress (Koss, 1991), low self-esteem, anger, and frustration (Brackenridge, 2002). Besides, the stigma that female players cannot perform as well as male players in online games has prevented female players from moving forward and being successful in the esports industry (Fox \& Tang, 2014). Furthermore, in some situations, female players were removed from the game or replaced with a male player due to gender stereotyping, which caused female players to work harder to be in the highest rank (Lowrie \& Jorgensen, 2011) in an online game. Besides, the pay and prizes were also inconsistent between female and male players. On average, female players earned USD 3,331.18 compared to the average winning amount collected by male players, which was USD 443,276.80, according to a study conducted by the Entertainment Software Association (ESA) with a difference of $751 \%$ (Shaw, 2012).

Based on the literature review that has been highlighted, esports itself has a new area and therefore not many studies have been conducted especially in the sociology field. Many researches on esports more focused on the evolution of esports, factors involving in esports and the effects of involving in esports. While there is not much research highlighted on gender differentiate among esports athletes. Statistics showed that esports are nominated by male athletes compare to female. This statistic is interesting to study why it happens. Gender role theory may influence the numbers of female participation in esports. According to gender theory, gender socialization since baby has determined what type of clothes, toys, sport, and job that can be done by male or female. Challenges faced by female athletes said by previous research including the challenges to be in the main team, played the main role, often being underestimated of their capabilities and sometimes they were faced-sexual harassment. The lack of the existing research is they do not explore more 
on how the female's athlete overcome their challenges or to what extend the challenges affect their confidence and career in esports. Apart from that, many researches that have been done were used a quantitative approach and all the research were conducted outside of Malaysia. Malaysia is one of the countries that really take serious on esports and through the Ministry of Youth and Sports Malaysia, the blueprint of esports has been introduced and Malaysia targeted to be the numbers one hub of esports in Asia within five years. Therefore, a study on Malaysia setting need to be done because, the differences between culture, locality and esports management also will lead to the different outcome. Thus, this study tries to fill the gaps from the previous researches.

\section{METHODOLOGY}

This study used a qualitative approach to obtain data and information from esports athletes. As this study focused on the gender stereotype issue, a qualitative method was viewed as one of the most practical approaches where researchers have the flexibility in questioning the respondents. An in-depth interview was conducted with ten respondents.

The respondents were selected using a non-probability sampling method, that is, intended sampling. For this study, the respondents' inclusion criteria were the respondents should be female, an esports player, aged between 18 to 30 years, and registered with an esports club. The justification for selecting respondents in the mentioned age range is most esports players are made up of this age group. The importance of selecting a registered respondent with an esports club is due to the esports concept itself, where players represent a team/club in a single match. Additionally, data from secondary sources were also referred to for more information. This study's results were analyzed using a thematic method, where the author compiled the interview session results with several pre-defined themes. All the themes were explicitly designed to address the research issues. Data were presented descriptively and narratively.

\section{RESULTS AND DISCUSSION}

\section{Profile of Esports Female Respondents}

Seven respondents were interviewed in this study, and their details are as follows.

Table 1 shows the informants were in the age range between 19 and 22 years old and were registered under three esports clubs, namely NED Esports, Weak Esports, and Girls Power. Informant D, G, and J were with the least experience in esports with one-year of experience of being professional female players. Meanwhile, Informants A, $\mathrm{C}, \mathrm{E}, \mathrm{H}$, and I, were involved in esports for two years. The most experienced players in this study were Informants F and B, who have been in the Malaysian esports industry for three years. Although the professional involvement period in esports was relatively short, ranging from one to three years, the informants were actively involved and exposed to video games for a long time. Nevertheless, their tenures as professional gamers were classified as a new level. 
Table 1

Profile of respondents

\begin{tabular}{ccc}
\hline Informants & Age (years) & $\begin{array}{c}\text { Duration involved in Esports } \\
\text { (years) }\end{array}$ \\
\hline A & 21 & 2 \\
B & 20 & 3 \\
C & 21 & 2 \\
D & 19 & 1 \\
E & 22 & 2 \\
F & 20 & 3 \\
G & 19 & 1 \\
H & 22 & 2 \\
I & 19 & 2 \\
J & 20 & 1 \\
\hline
\end{tabular}

\section{Factors Affecting Involvement of Female Athletes in Esports}

Most respondents stated that they were interested in playing video games since they were in high school, where they found that was the motivation in choosing esports as a career. Informant D, the youngest respondent in this study, added:

I do have a passion for video games, but I just play for fun to reduce my stress and to spend my leisure time. Never once I thought I would end up being a professional gamer, and I do see that one can make money within this industry (Informant D).

The situation shows that playing video games is no longer considered a negative habit. Previous studies linked involvement in video games becomes an addiction (Gentile et al., 2011; Ozlan \& Buzlu, 2007), educational neglect (Griffiths, 2010), motivates players to be aggressive and violent (Lehenbauer-Baum \& Fohringer, 2015) and can also cause health problems (Young, 2009). Video games can also offer many benefits to players. One of the benefits includes the lucrative returns of a professional player's salary or the tournaments' prizes.

Apart from interest or hobby, another factor that encouraged the respondents' engagement in esports is peer influence. Peers are important socializing agents who can be a catalyst for another person's behavior. According to Informant B:

I was not good at video games previously. I play very simple games such as candy crush and arcade. But, I have a few friends who are good at games. Especially strategic games like MOBA and Headstone. I did not understand the games initially but after I watched my friends playing and they won, I was excited and asked 
my friends to teach me to play those strategic games (Informant B).

Informant $\mathrm{B}$ added that close friends play an important role in teaching how to play MMORPG. At first, it was fun to play video games, but realizing that the MMORPG requires strategy and skills, eventually sparked interest in learning the game. Informant $\mathrm{G}$ also agreed with Informant's B statement, and she added:

Multiple Role Player such as PUBG, MOBA or DOTA are kind of difficult games. The tricky part is that you must understand how to play the game, then you have to come out with the strategy of how to win the game. Communication with team members is important. Because MMORPG is a team-based game. If you don't have communication with your team members, for sure you cannot win the game (Informant G).

Communication with team members is crucial in winning a game, especially in a team-based game such as MMORPG. Each player has a specific role in ensuring that the team wins (Yee, 2006). Team members are considered friends. Besides the communication aspect, trust among team members is very important to win the game (Huang et al., 2013).

Apart from personal interest, peer influence, and communication skills, social media also influenced female players' involvement in esports. Social media's role is significant, where more interactions occur via social media than face-to-face communications. Respondents also stated that online games live advertisements that appear while using Facebook and YouTube could also initiate the interest to become a professional esports player. According to Informant D:

I play video games for quite long but just for fun or to compete with my friends. I have never thought of being a professional online game player as many female players I came across were not professional players. Once when I was using YouTube, I found out some female gamers actively streaming their live games. Then, I started to follow them, and it is very interesting as you can do whatever you like, and you will be paid for your hobby you are passionate about (Informant D).

YouTube is an excellent platform for streaming live online games, which means that a player's game will be watched by hundreds of thousands of people online. Viewers can comment when a player plays, and the player can interact with the audience (Webster, 2013). This phenomenon attracts informal gamers to venture into the esports industry as professional players. Informant D mentioned that the live streaming method could generate huge revenue depending on how many viewers are watching and how long a player can survive the game. 


\section{The Challenges Faced by the Informants}

As mentioned earlier, the esports industry is pioneered by men. While some female players have made it through the industry, it has not been an easy journey. All the informants acknowledged that they faced several challenges throughout their careers. The gender stereotyping issue has been the biggest challenge they experienced. Although all informants have one to three years of experience in the industry, they still face gender stereotyping. The informants who participated in this study agreed that the main reason for poor involvement by female players' in esports is due to gender inequality (Ferrante, 2011). Gender equality is a major agenda promoted by the United Nations through the Sustainable Development Goals. Eliminating discrimination against girls and women is important in all areas, including sports institutions (Department of Economic and Social Affairs, n.d.). Gender equality will not be achieved if gender role stereotype still occurs. Through socialization, society has determined what a woman and a man can do in terms of clothes, toys, behavior, and career choices. This situation has indirectly influenced the belief that gender roles cannot be changed even though they are flexible and can change over time, culture, and locality.

You know that online games are dominated by men, so when female like me decided to be a professional player, there is always someone talking bad about it. I had an experience with one male player where he asked female can play online games? Better you go home, stay in the kitchen and learn how to cook. That is more appropriate (Informant E).

Classification of what a woman can and cannot do caused the respondents to experience the stigma. The male players often feel it is inappropriate for women to play video games. One of the main reasons this happen because the culture in Malaysia specifically not allowed female to spend much time in front of smartphones or computer. Parents normally have many list to do for their daughters and most of them are house chores. While for male, they always get some 'approval' spending their time playing video games. According to Informant $\mathrm{H}$ :

"I used to be stigmatized by male players. Once when I signed up for a competition, my rival was a male and asked do you know how to play?" (Informant $\mathrm{H}$ ).

The situation shows that the opponent player underestimated the ability of the respondent in the competition. This study's results were in line with those found by Beasley and Collins (2002), who stated that female esports athletes are often doubted for their ability to play against their opponents. Furthermore, Hartmann and Klimmt (2006) added that sometimes opponents underestimate female players assuming they can play with ease. When their scores were interrupted by female 
players, the male players will play on gender sentiment to provoke opponents to lose focus on the game. The respondents also stated they did not receive the same respect as the male players. However, they feel that they can play alongside men but being in the industry is difficult.

I join this industry more than three years ago. I have participated in many competitions and I won several times and achieved top rank. However, I still did not get any attention and respect from the others especially the male players (Informant $\mathrm{G}$ ).

Although the respondents were successful in the competition, they still feel that they did not receive the same recognition and respect as the men. At times, there were cynical remarks stating that the respondents' victory was merely a stroke of luck. Female players also face communication issues, especially when they are in a team of male players. As Informant A said:

"Before I joined my current team, I used to be with a team where I was the only female athlete and faced communication problem" (Informant A).

Previously, she was the only female player in a team that consisted of male players. Communication between team members is crucial in MMORPG games. Strategies need to be carefully crafted; players need to know their roles and decide who plays the main role and hold the supporting role. Since Mojo is a young woman, her valuable suggestions were sometimes not accepted by others. They seem to think that men are better at playing MMORPG games than women. Thus, Mojo chose to leave her old team and be a member of her current team, comprising female players only. Communication problem sometimes because of gender differences while the man tends to show their masculinity.

Being in the same group as her gender, she felt that the stresses being in the team had diminished. Communication is smooth and can work with other team members to develop strategies to ensure success in competitions. They also focus on participating in tournaments that focus on women's esports. It is more fun as there is no stereotyping or gender discrimination in competitions dedicated to female players.

Informants also mentioned that they were usually given supporting roles in the competition that involved both female and male players. Male players dominate the main character due to the stigma women are not good game players. Thus, men are always given the leading role (Ivory, 2006). Despite being with the team for a long time and the management team was aware of their development and ability, they still failed to be the lead player, doubting their ability to win a game. There were cases where male players were selected as the main character in a match but could not perform well yet could still play as the main character in the next game. Female players remain as the supporting role in a game. 
This situation has directly hindered the opportunity and space for female players to develop their potential in games and competitions, reducing their confidence level in their ability to perform equally as men. If this situation continues, many female players cannot undertake the online gamer profession in the future. Gender inequality exists in esports as in other fields. Respondents mentioned that female players' abilities were sometimes overlooked because of gender stereotyping. Informant D added:

Even though you did not wear a sexy attire during the tournament since you wear team attire, which is normally a T-shirt and jeans, yet we received some sexism comments from other opponents. For instance, a question like your avatar is very sexy are you the same as this avatar? (Informant D).

Female players were often given the supporting role, a weak female animation character or avatar, and they need to be rescued by the team members. The animated women's images were usually sexy with their exposed bodies and skin (Fox \& Tang, 2016). Some male players assumed that the character's appearance in the game played by the respondents reflects their image in real life. Sometimes respondents were given sexist comments even though they are not sexy in real life. The images influenced the opponents to express such views. As such, female players should be allowed to hold the helm for a long time because they want to avoid this kind of situation. These sexually explicit comments can eventually be categorized as sexual harassment against female players (Fox et al., 2015).
I agree, that is why when I first became a professional player, I did not use a nickname that represents a female player. It is because I want to avoid receiving sexism comments and do not want to be stigmatized just because I am a female (Informant C).

To avoid being labeled and receiving sexist comments, the respondents avoided using female nicknames. When Wenny decided to become a professional esports player, she decided not to use a nickname to indicate her as a female. Names like Kingston and Richminds were the names that Wenny used before she joined the female clubs. No comments on gender stereotypes were made against her when she used those names. The respondents also stated that they were excluded from participating in big tournaments due to gender stereotyping. The esports competition has many levels, from league to international level, reflecting different types and prizes to be won. In international matches, the prizes are usually paid in US dollars. According to Informant B:

"In this industry, we the female players have very little chance to represent the country, especially in the international tournaments. Although you are good in playing the games yet comparison will be made with the male players" (Informant B).

Female players need to be good in the game if they want to be selected for international competitions representing the 
country. Male players dominate the industry and usually win competitions at national and international levels. The respondents stated that the opportunities given to male players were regarded too challenging for the female players in the esports industry. To achieve equality on gender, female should not be underestimated of their capabilities and they should give more chances to participate and grow in esport career. The older thought of women cannot be an esports athlete because this sport is not suitable for them, need to be changed. Living with the world of technologies, the setting of sport and job also has changed. Being an esports player shows that women are ready to take a chance to explore the new area and breaking the nomination of male in industries. Although for some people, esport is not a guaranteed career but with the strong will, hard work and motivation to excel surely the female can succeed if they get their opportunity and treated equally as male athletes.

\section{CONCLUSION}

Malaysia aspires to become the hub for Asian esports. Numerous exposures and tournaments have been organized. An injection of funds by the Ministry of Youth and Sports also shows its commitment to achieving this goal. However, all these efforts are impossible if gender stereotyping issues still prevail in Malaysia's esports industry. While the ministry, the competition organizers, and the esports clubs' welcome women's entry into this industry, it is not easy as expected. Female esports players had to deal with various challenges related to gender stereotype issues before and after choosing to be a part of esports.

It is undeniable that female esports players have their strengths and capabilities. Successful female esports players must face many challenges. Authorities such as the Ministry of Youth and Sports, the Esports Association of Malaysia (ESM), and the management of esports clubs should be aware of the issues related to gender stereotypes. Opportunities for female esports players should not be compromised. The number of women participating in esports will diminish as these groups will not be able to handle the gender stereotyping issues. In conclusion, despite the gender stereotyping issues faced by the female players, they remain in the industry for their intense interest in video games. Nonetheless, this interest could also fade if gender inequality in the industry prevails.

\section{ACKNOWLEDGEMENT}

Thanks to the grant FRGS/1/2019//SS06/ $\mathrm{UKM} / 02 / 5$ for financial support toward this research.

\section{REFERENCES}

Beasley, B., \& Collins, S. T. (2002) Shirts vs. skins: Clothing as indicator of gender role 2.0 applications for learning in higher education. The Internet and Higher Education, 16, 57-65. https://doi.org/10.1207/S15327825MCS0503_3

Bettencourt, B. A., \& Miller, N. (1996). Gender differences in aggression as a function of provocation: A meta-analysis. Psychological Bulletin, 119(3), 422-447. https://doi. org/10.1037/0033-2909.119.3.422 
Blumberg, F. C., \& Sokol, L. M. (2004). Boys' and girls' use of cognitive strategy when learning Debunking the gender performance gap in two massively multiplayer online games. Journal of General Psychology, 131(2), 151-158. https:// doi.org/10.3200/GENP.131.2.151-158

Bonanno, P., \& Kommers, P, M. (2008) Exploring the influence of gender and gaming competence on attitudes towards using instructional games. British Journal of Educational Technology, 39(1), 97-109. https://doi.org/10.1111/j.14678535.2007.00732.x

Brackenridge, C. H. (2002). "So what?" Attitudes of the voluntary sector towards child protection in sports clubs. Managing Leisure - An International Journal, 7(2), 103-124. https:// doi.org/10.1080/13606710210139857

Bradmore \& Magus. (2016, December 7). League of Legends world championship by the numbers. Lolesports. http:/www.lolesports.com/en_US/ articles/2016-league-legends-world

Chan, E. Y. (2008). Females' video game playing motivation and performance: Examining females' gaming performance. Computers in Human Behavior, 59, 202-209.

Chikhani, R. (2015, October 31). The history of gaming: An evolving community. Techcrunch. https://techcrunch.com/2015/10/31/the-historyof-gaming-an-evolving-community/

Department of Economic and Social Affairs. (n.d.). The 17th Goals. United Nations. https://sdgs. un.org/goals

Edwards, T. F. (2013, April 19). ESports: A brief history. Adanai. http://adanai.com/esports

Everson, J. (2013, March 19). Why do MOBA's make such good eSports games? Gameskinny.com. http://www.gameskinny.com/avpgu/why-domobas-make-suchgood-esports-games

Ferrante, J. (2011). Seeing sociology: An introduction. Cengage Learning.
Fox, J., Ralston, R., Cooper, \& Jones, K. (2015). Sexualized avatars lead to women's selfobjectification and acceptance of rape myths. Psychology Women Quartile, 39, 349-362. https://doi.org/10.1177/1461444816635778

Fox, J., \& Tang, W. Y. (2014). Sexism in online video games: The role of conformity to masculine norms and social dominance orientation. Computers in Human Behavior, 33, 314-320. https://doi.org/10.1016/j.chb.2013.07.014

Fox, J., \& Tang, W. Y. (2016) Women's experience with general and sexual harassment in online video games: Rumination, organizational responsiveness, withdrawal, and coping strategies. New Media and Society, 1, 1-18. https://doi.org/10.1177/1461444816635778

Gentile, D. A., Choo, H., Liau, A., Sim, T., Li, D., Fung, D., \& Khoo, A. (2011). Pathological video game use among youths: A two-year longitudinal study. Pediatrics, 127(2), e319-e329. https://doi. org/10.1542/peds.2010-1353

Gray, K. L. (2012). Deviant bodies, stigmatized identities, and racist acts: Examining the experiences of African-American gamers in Xbox live. New Review in Hypermedia and Multimedia, 18(4), 261-276. https://doi.org/10 $.1080 / 13614568.2012 .746740$

Griffiths, M. (2010). Online video gaming: what should educational psychologists know? Educational Psychology in Practice, 26(1), 3540. https://doi.org/10.1080/02667360903522769

Hamari, J. (2013). Transforming homo Economicus into Homo Ludens: A field experiment on gamification in a utilitarian peer-to-peer trading service. Electronic Commerce Research and Applications, 12(4), 236-245. https://doi. org/10.1016/j.elerap.2013.01.004

Hamari, J., \& Sjöblom, M. (2017). What is eSports and why do people watch it? Internet Research, 27(2), 211-232. https://doi.org/10.1108/IntR04-2016-0085 
Hartmann, T., \& Klimmt, C. (2006). Gender and computer games: Exploring females' dislikes. Mass Communication and Society, 9(1), 103-114. https://doi.org/10.1111/j.10836101.2006.00301.x

Hayes, E. (2007). Gendered identities at play: Case studies of two women playing Morrowind. Games and Culture, 2(1), 2-23. https://doi. org/10.1177/1555412006294768

Huang, W. H. D., Hood, D. W., \& Yoo, S. J. (2013). Gender divide and acceptance of collaborative Web. Multimedia, 18, 261-276. https://doi.org/ $10.1080 / 13614568.2012 .746740$

Ivory, J. D. (2006). Still a man's game: Gender representation in online reviews of video. Mass Communication and Society, 9(1), 103-114. https://doi.org/10.1207/s15327825mcs0901_6

Kaye, L. K., \& Pennington, C. R. (2016). "Girls can't play": The effects of stereotype threat on to play video games. The Journal of General Psychology, 131(2), 151-158.

Koss, M. P. (1991). Changed lives: The psychological impact of sexual harassment. Research, 27(2), 68-80.

Lee, D., \& Schoenstedt, L. J. (2011). Comparison of eSports and traditional sports consumption motives. The ICHPER-SD Journal of Research in Health, Physical Education, Recreation, Sport \& Dance, 6(2), 39-44.

Lehenbauer-Baum, M., \& Fohringer, M. (2015). Towards classification criteria for internet gaming disorder: Debunking differences between addiction and high engagement in a German sample of world of warcraft players. Computers in Human Behavior, 45, 345-351. https://doi. org/10.1016/j.chb.2014.11.098

Lowrie, T., \& Jorgensen, R. (2011). Gender differences in students' mathematics game playing. Computers \& Education, 57(4), 2244-2248. https://doi.org/10.1016/j.compedu.2011.06.010
Lynch, A. (2016, May 20). Tracing the 70-year history of video games becoming eSports. Foxsports. https://www.foxsports.com/stories/other/tracingthe-70-year-history-of-video-games-becomingesports

Milne, G. R., \& McDonald, M. A. (1999). Sport marketing: Managing the exchange process. Jones and Bartlett.

Nielsen. (2009). Insights on casual games: Analysis of casual games for the PC. Norms and social dominance orientation. Computers in Human Behavior, 33, 314-320.

Ozlan, N. K., \& Buzlu, S. (2007). Internet use and its relation with the psychosocial situation for sample of university students. Cyberpsychology and Behavior, 10(6), 767-772. https://doi. org/10.1089/cpb.2007.9953

Ray, S. G. (2004). Gender inclusive game design: Expanding the market. Hingham.

Ruvalcaba, O., Shulze, J., Kim, A., Berzenski. S. R., \& Otten, M. P. (2018). Women's experiences in esports: Gendered differences in peer and spectator feedback during competitive video game play. Journal of Sport and Social Issues, 42(4), 295-311. https://doi. org/10.1177/0193723518773287

Salleh, M. A. M., Ekhwan, Z., \& Salman, A. (2019). Mudah guna dan manfaat aplikasi WhatsApp terhadap hubungan antara peribadi masyarakat dan polis [Ease of use and usefulness of WhatsApp application in interpersonal relationship between community and police]. Jurnal Komunikasi: Malaysian Journal of Communication, 35(4), 135-154. https://doi. org/10.17576/JKMJC-2019-3504-09

Salleh, M. A. M., \& Ilham, N. M. M. (2017). Pengalaman dan kesedaran pengguna dewasa terhadap isu pengawasan di media sosial [The experience and awareness of adult users of surveillance issues in social media]. Jurnal Komunikasi: Malaysian Journal of 
Communication, 33(1), 502-514. https://doi. org/10.17576/JKMJC-2017-3301-33

Shaw, A. (2012). Do you identify as a gamer? Gender, race, sexuality, and gamer identity. News Media and Society, 14(1), 28-44. https://doi. org/10.1177/1461444811410394

Shen, C., Ratan. R., Cai. Y. D., \& Leavitt, A. (2016). Do men advance faster than women? Stereotyping in video games. Mass Communication and Society, 5, 279-293. https://doi.org/10.1111/jcc4.12159

Webster, A. (2013, January 21). Don't die: Live streaming turns video game speed runs into a spectator sport. The Verge. http://www.theverge. com/2013/1/21/3900406/video-gamespeedrunsas-live-spectator-sport

Witkowski, E. (2014). Girl gamers? Player and institutional orientations towards women's participation in and around e-sports. AoIR Selected Papers of Internet Research, 4. https:// journals.uic.edu/ojs/index.php/spir/article/ view/8622
Yee, N. (2006). The demographics, motivations and derived experiences of users of massivelymultiuser online graphical environments. Presence: Teleoperators and Virtual Environments, 15(3), 309-329. https://doi. org/10.1162/pres.15.3.309

Young, K. S. (2009). Understanding online gaming addiction and treatment issues for adolescents. The American Journal of Family Therapy, 37, 355-372. https://doi. org/10.1080/01926180902942191

Yusoff, N. H. (2020). The need of crime prevention through environmrntal design (CPTED) to prevent misbehavior among Malaysian football fans. Journal of Xi' an University of Architecture \& Technology, XII(IV), 3804-3808.

Yusoff, N. H., Tahir, Z., Lyndon, N., Mohd Yunus, Y. H., \& Abu Hasan, N. (2020). Wanita dan e-sukan di Malaysia: Sosialisasi dan stereotaip gender [Women and e-sports: Socialization and gender stereotype]. Jurnal Komunikasi: Malaysian Journal of Communication, 36(4), 442-457. 
